\title{
Combined mass and energy integration in process design at the example of membrane-based gas separation systems
}

\author{
Martin Gassner, François Maréchal \\ Laboratory for Industrial Energy Systems, Ecole Polytechnique Fédérale de Lausanne \\ CH - 1015 Lausanne, Switzerland \\ Computers and Chemical Engineering (2010), doi:10.1016/j.compchemeng.2010.06.019
}

\begin{abstract}
This paper presents an approach for combined mass and energy integration in process synthesis and illustrates it at the thermochemical production of crude synthetic natural gas (SNG) from lignocellulosic biomass and its separation in a membrane cascade. Based on a general process superstructure, the design problem is decomposed into non-linear unit models whose energy and mass balances are used as constraints in mixed integer linear programming (MILP) that targets the maximum combined production of fuel, heat and power. The flowsheet structure and its operating conditions are thereby considered as complicating decision variables in an overall non-linear and non-continuous optimisation problem that is addressed with an evolutionary, multi-objective optimisation algorithm. In a process that uses its waste and intermediate product streams to balance the heat demand, such a formulation allows for identifying intensified, overall optimal flowsheets by considering all aspects of the process design.
\end{abstract}

Keywords: energy integration, mass integration, process integration, membrane system design, process design

\section{Nomenclature}

\author{
Abbreviations \\ CHP Combined heat and power \\ (FIC)FB (Fast internally Circulating) Fluidised bed \\ HEN Heat exchanger network \\ MI(N)LP Mixed integer (non-)linear programming \\ SNG Synthetic natural gas \\ Greek letters \\ $\Delta \tilde{h}_{r}{ }^{0} \quad$ Standard heat of reaction \\ $\Delta h^{0} \quad$ Lower heating value \\ $\varepsilon \quad$ Energy efficiency \\ $\Phi \quad$ Humidity \\ $\theta \quad$ Molar stage cut \\ Roman letters \\ A Membrane area \\ C Cost \\ c Mass fraction \\ $\tilde{c} \quad$ Molar fraction \\ $c_{p} \quad$ Specific heat at constant pressure \\ $\dot{E} \quad$ Mechanical or electrical power
}

$$
\begin{array}{r}
\mathrm{kJ} / \mathrm{mol} \\
\mathrm{kJ} / \mathrm{kg} \\
\% \\
\mathrm{~kg}_{H 2 O} / \mathrm{kg}_{\text {tot }} \\
- \\
\mathrm{m}^{2} \\
€ \text { or } € / \mathrm{MWh} \\
\% \\
\% \\
\mathrm{~kJ} /(\mathrm{kg} \mathrm{K}) \\
\mathrm{kW}
\end{array}
$$


$f_{s} \quad$ Utilisation level of subsystem $s$

$h \quad$ Mass enthalpy $\quad \mathrm{kJ} / \mathrm{kg}$

$i_{r} \quad$ Interest rate $\%$

$\dot{m} \quad$ Mass flow $\mathrm{kg} / \mathrm{s}$

$p$ Pressure bar

$\dot{Q} \quad$ Heat $\quad$ kW

$\dot{R} \quad$ Cascaded energy $\quad$ kW

$r_{S / B} \quad$ Steam to dry biomass ratio

$T \quad$ Temperature $\quad \mathrm{K}$

$y_{s} \quad$ Integer variable for existence of subsystem $s$

Subscripts

ad adiabatic

c Combustion

d Drying

el electric

$f \quad$ feed

$g \quad$ Gasification

$m \quad$ Methanation

$\max$ maximum

$\min$ minimum

$p \quad$ permeate

$s \quad$ Steam cycle

th thermal

Superscripts

$+\quad$ Material or energy stream entering the system

- Material or energy stream leaving the system

$0 \quad$ Standard conditions

\section{Introduction}

In the field of process synthesis, the process integration addresses the analysis and synthesis of interactions between the process unit operations. According to Grossmann (1996), a major part of the research for optimisation-based design approaches is yet restricted to process subsystems. A large emphasis is thereby put on heat integration, heat exchanger network (HEN) synthesis and utility and energy recovery system design. Considerable effort has also been spent for investigating methods for realising the mass integration in reaction, separation and recovery networks.

Many of the approaches exploit analogies between mass and energy transfer in pinch analysis and network synthesis by mathematical programming techniques. Combined methods for mass and energy integration and global process optimisation are however rare. Addressing the synthesis of reaction and separation subsystems to design intensified and more efficient processes is still a challenge, for which superstructure concepts are expected to be appropriate (Grossmann, 1996). This paper presents such an approach applied to the separation of crude synthetic natural gas (SNG) produced from biomass.

\subsection{Motivating example}

The thermochemical conversion of lignocellulosic biomass to methane is a promising way to distribute a renewable resource as a versatile energy vector in an existing grid. Potentially more efficient than the production of liquid fuels (cf., for example, Mozaffarian and Zwart (2003); Gassner and Maréchal (2009b); Tijmensen et al. (2002); Tock et al. (2010)), it can be used in the form of synthetic natural gas (SNG) as automotive fuel or in combined heat and power (CHP) applications at any scale.

For a typical biomass composition, the thermochemical production of SNG targets the complete 


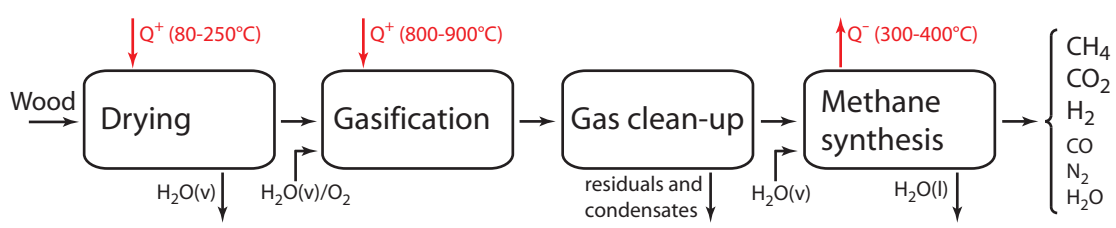

Figure 1: Block flow diagram of crude SNG production from wood (Gassner et al., 2009).

\begin{tabular}{lcccccc}
\hline & $\mathrm{C}_{2} \mathrm{H}_{4}$ & $\mathrm{CH}_{4}$ & $\mathrm{H}_{2}$ & $\mathrm{CO}$ & $\mathrm{CO}_{2}$ & $\mathrm{~N}_{2}$ \\
\hline Gasification & $2-6$ & $9-12$ & $27-42$ & $15-28$ & $18-38$ & $0.1-1(3)$ \\
Methanation & - & $40-49$ & $1-7$ & $<0.2$ & $44-58$ & $0.2-1$ \\
- without $\mathrm{CO}_{2}$ & - & $86-96$ & $3-12$ & $<0.4$ & - & $0.5-2$ \\
\hline Grid specifications & & $>96$ & $<4$ & $<0.5$ & & $<6$ \\
\hline
\end{tabular}

Table 1: Typical raw gas composition and grid specifications in \%vol, dry (Gassner and Maréchal, 2009b; Gassner et al., 2009).

conversion according to the conceptual overall reaction (1):

$$
\mathrm{CH}_{1.35} \mathrm{O}_{0.63}+0.3475 \mathrm{H}_{2} \mathrm{O} \longrightarrow 0.51125 \mathrm{CH}_{4}+0.48875 \mathrm{CO}_{2}, \quad \Delta \tilde{h}_{r}^{0}=-10.5 \mathrm{~kJ} \mathrm{~mol}_{\text {biomass }}^{-1}
$$

This conversion to methane requires catalytic action, and the currently most envisaged technical route is based on two reactive steps. First, the biomass is endothermally decomposed above typically $800 \mathrm{C}$ by gasification to a producer gas rich in $\mathrm{H}_{2}, \mathrm{CO}, \mathrm{CO}_{2}$ and $\mathrm{CH}_{4}$. After cleaning the gas from tars and impurities (mainly traces of nitrogen, sulphur, chlorines and metals) to prevent equipment fouling and catalyst deactivation, methane is exothermally synthesised in a catalytic bed. As illustrated on the block flow diagram for crude SNG production depicted in Figure 1, drying of the raw material is furthermore required to limit the demand of high-temperature heat for water evaporation. The most promising candidate technologies for these processing steps are discussed and modelled by Mozaffarian and Zwart (2003) and Gassner and Maréchal (2009b).

Methane synthesis is limited by chemical equilibrium at a sufficiently high temperature of 300 to $400^{\circ} \mathrm{C}$ to maintain feasible reaction kinetics. The conversion of Eq.(1) is thus not complete, and residual hydrogen and carbon monoxide are obtained. Allowing for some additional leakage of Nㅡ, the typical raw gas compositions of Table 1 illustrate that the removal of only $\mathrm{CO}_{2}$ is not sufficient to reach grid quality of natural gas. Further purification from at least hydrogen is thus necessary.

Apart facing a multicomponent problem, a second aspect in the design of the separation system is that gasification is endothermal and requires heat at high temperature. In the candidate technology developed by Hofbauer et al. (2002) at which Biollaz et al. (2009) have demonstrated a novel methanation reactor design, this heat is provided indirectly from an adjacent combustion reactor by recirculating bed material and ungasified char. As an alternative to the cold, clean producer gas that is used to balance the heat demand in the CHP plant, depleted streams from the separation may be valorised as combustibles in case of SNG production.

Discussed in more detail by Gassner et al. (2009), these considerations indicate that process efficiency and economics may benefit from an overall formulation of the mass- and energy integration problem, which allows for optimising the process design by taking all its aspects into account.

\subsection{Approaches for the design of membrane cascades}

The problem of the membrane cascade design for gas purification has been considered by several authors. Bhide and Stern (1993) have presented a comprehensive analysis of seven membrane system configurations from single- to three-stage systems with recycling. After the heuristic generation of the configurations, each of the membrane systems is subsequently optimised separately using a "case study" method. Agrawal (1997) addresses the problem by systematically synthesising membrane systems with 
a limited number of compressors and by introducing heuristic rules to find the best system configuration. Qi and Henson (2000) have proposed a mixed integer non-linear programming (MINLP) model based on a superstructure approach. The problem is solved using an outer approximation algorithm. Vince et al. (2008) propose an alternative multi-objective MINLP optimisation strategy to design isolated membrane systems for water desalination. The method uses a superstructure concept to synthesise the membrane system configuration and decomposes the optimisation into a master and slave problem. While the master program is solved with a multi-objective, evolutionary algorithm, the slave problem is solved using conventional MILP techniques to extract the optimal process configurations from a membrane cascade superstructure.

All these studies address the design of isolated membrane cascades without considering interaction with the heat balance of a plant.

\subsection{Mass and energy integration for waste recovery}

The problem of mass and energy integration has most of the time been addressed in the field of water recycling and mass exchange network design. In pioneering work, El-Halwagi and Manousiouthakis (1989) and co-workers have addressed the design of combined heat and mass recovery networks by applying the analogy between heat and mass transfer. In this approach, the use of membrane systems could be one of the alternatives for mass integration (El-Halwagi, 1992). In subsequent studies, Dunn and El-Halwagi (2003) have addressed the principle of process integration techniques with an emphasis on mass and heat integration. Bagajewicz et al. (1998) investigate a superstructure approach to solve mass exchange and heat exchange networks. They highlight the analogy between heat and mass integration by applying a "state-space" concept. Isafiade and Fraser (2009) propose an approach that combines heat and mass integration by applying interval-based MINLP superstructure concepts that are introduced by the authors.

Although the general problem of mass and energy integration has already been addressed, the combined problem that considers the synthesis of the separation system together with the valorisation of the waste streams as heat source for the process heat integration has never been systematically tackled in the past. This is the purpose of this paper. In Sections 2.1 to 2.3, we present an appropriate problem decomposition to introduce a membrane cascade design model into a more general process system design methodology which allows for exploiting the synergies between the different subsystems at the overall system level. Section 2.4 provides the integration model used to calculate the conversion of the waste streams of the gas purification section to solve the problem of the overall process integration. The global process optimisation with a multi-objective algorithm is then discussed at the example problem in Section 3.

\section{Problem formulation}

\subsection{Decomposition}

In the general outline of a methodology for the optimal conceptual design of thermochemical production of fuels from biomass (Gassner and Maréchal, 2009a), we have introduced an appropriate model decomposition for an efficient generation of a set of thermo-economically optimal process configurations. Based on the classical sequential design approach of Douglas (1988), Kravanja and Glavic (1997) have formulated a mathematical programming problem in which the optimal heat exchanger network (HEN) for energy supply from external utility streams is targeted. In our case, there are no utility streams and the waste and intermediate process streams itself must be considered to supply the required heat for the conversion. The process model used in the flowsheet generation step has therefore to be formulated in order to determine the appropriate streams and flowrates for this purpose. In addition, it should allow for computing the optimal combined heat and power cogeneration to valorise the excess exergy from the process streams. An approach that inherently combines mass and energy integration is thus necessary. 


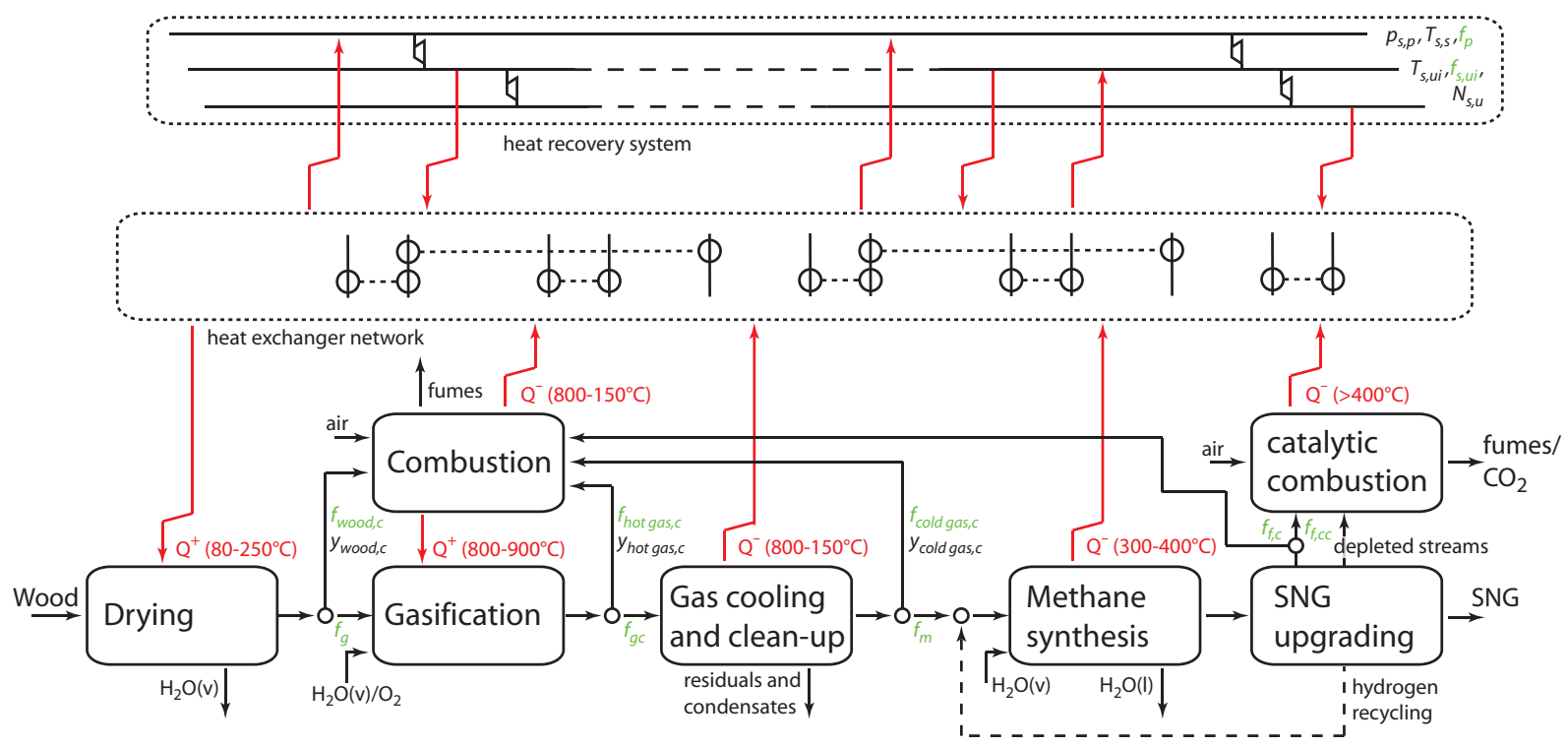

Figure 2: Conceptual structure of the process model including the heat exchanger network and energy recovery system (simplified). Non-linear process unit models are represented by boxes. Decision variables exclusively used in the MILP are highlighted in bold green.

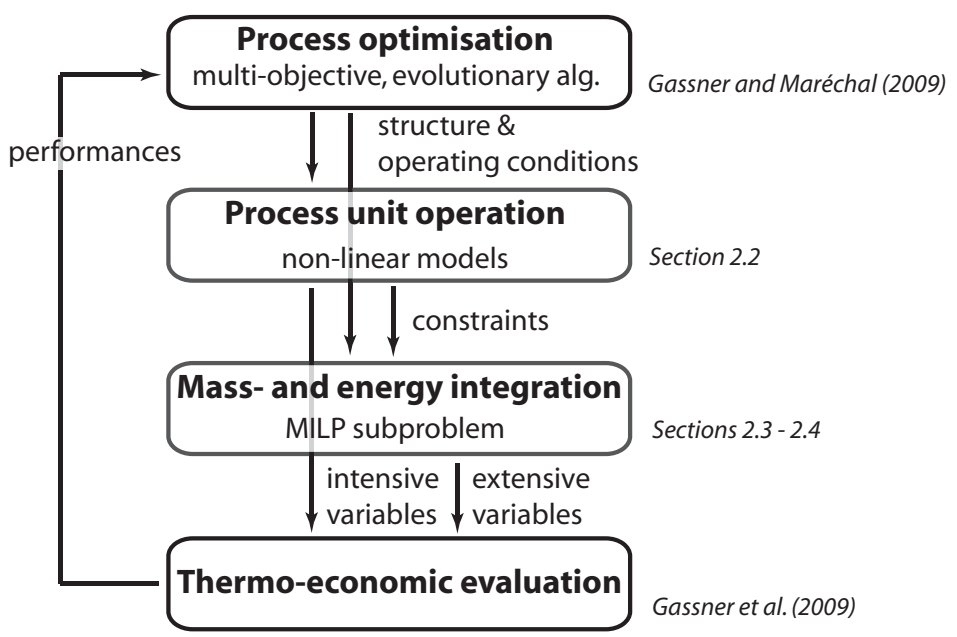

Figure 3: Computation sequence.

Taking the structure of the design problem into account, its formulation can be decomposed with respect to its mathematical nature. As illustrated in Figure 2, the process model can be divided into several non-linear unit models that represent the thermochemical conversion in the different process sections. While the optimal selection of technology, structure and operating conditions of these subsystems are to be determined with algorithms that are able to handle complicated non-linear and non-continuous problems, the optimisation of the mass and energy transfer between them can be addressed by mixed integer linear programming (MILP) and treated as a subproblem in which the combined fuel, heat and power production are maximised for fixed unit transformations. Accordingly, the process design is decomposed in two optimisation problems whose computation sequence is outlined in Figure 3. On the master level, an evolutionary, multi-objective algorithm assigns the complicating decision variables for the flowsheet structure and the operating conditions of its non-linear subsystems. The MILP subproblem then uses the mass and energy balances of the unit models as constraints and maximises the overall combined production for these specific conditions. 


\subsection{Process unit models}

For all subsystems $s$ of the problem, the chemical conversion of the process streams can be represented by a set of $j$ non-linear functions $\mathscr{F}_{s}$ :

$$
c_{j} \dot{m}_{j}^{-}=\mathscr{F}_{s}\left(c_{i}, \dot{m}_{i}^{+} \text {, operating conditions }\right) \forall j
$$

where $c$ and $\dot{m}$ are the mass concentrations and flows of the inlet and outlet streams $i$ and $j$, respectively. While $c_{i}$ and $c_{j}$ are vectors of varying size, $\dot{m}$ are scalars that obviously satisfy the mass conservation, i.e.:

$$
\sum_{j} \dot{m}_{j}^{-}=\sum_{i} \dot{m}_{i}^{+}
$$

Linked to the chemical conversion, the energy balance associated with $\mathscr{F}$ writes:

$$
\sum_{j_{h}}(\dot{m} h)_{j_{h}}^{-}+\dot{E}_{j}^{-}+\sum_{j_{t h}} \dot{Q}_{j_{t h}}^{-}=\sum_{i_{h}}(\dot{m} h)_{i_{h}}^{+}+\dot{E}_{i}^{+}+\sum_{i_{t h}} \dot{Q}_{i_{t h}}^{+}
$$

where $h$ refers to the total mass enthalpy, and $\dot{E}$ and $\dot{Q}$ represent the electricity and heat consumption or generation in the subsystem, respectively.

As the subsystem models are interdependent with respect to intensive variables such as stream composition, pressure and temperature, the formulation of $\mathscr{F}_{s}$ in Eq. (2) needs to balance model complexity and robustness of its numeric resolution. In general, the use of commercial flowsheeting software that supports the implementation of user-defined, phenomenological models is adequate for this purpose. In our case, the software developed by Belsim SA based on a simultaneous resolution of all model equations has proven convenient. The description of the unit models for SNG production used in this work is provided in Gassner and Maréchal (2009b). More details on the modelling of its multicomponent separation in a membrane cascade is given in Gassner et al. (2009), in which the design model for hollow fibre modules of Pettersen and Lien (1994) is implemented.

\subsection{Energy integration model}

Once the chemical conversion in the process sections and its associated heat requirements determined, the extensive part of the problem can be resolved by MILP in which both the mass balances between the subsystems and the heat cascade are used as constraints. The selection of the objective is thereby arbitrary as long as the aggregation of the terms is robust and consistent with respect to the multiple objectives of the master optimisation problem. In previous work (Gassner and Maréchal, 2009a), we proposed to minimise the total exergy depletion in the system. With such a formulation, the exergy efficiency of the plant is maximised in the MILP subproblem. A more straightforward alternative is yet to simply weight the product yields with respect to their energetic or economic value. For all subsections $s$ that provide $j$ output and consume $i$ input streams through the system boundary, the target can be expressed as a function of their utilisation level $f_{s}$ to be optimised, i.e.:

$$
\max _{\dot{R}_{r}, y_{s}, f_{s}} \sum_{s} f_{s}\left(\sum_{j}(\dot{m} h)_{j}^{-} C_{j}-\sum_{i}(\dot{m} h)_{i}^{+} C_{i}\right)+\left(\dot{E}^{-}-\dot{E}^{+}\right) C_{e l}
$$

subject to:

1. Existence of subsystem $s$ :

$$
f_{\min , s} y_{s} \leq f_{s} \leq f_{\max , s} y_{s} \quad y_{s} \in\{0,1\}, \forall s=1, \ldots, N_{s}
$$

2. Superstructure model:

$$
A f=b
$$

$$
A:\left(N_{s} \times N_{s}\right), f, b:\left(N_{s} \times 1\right)
$$


3. Heat balance of the temperature intervals $r$ :

$$
\sum_{s=1}^{N_{s}} f_{s} \dot{Q}_{s, r}^{-}+\dot{R}_{r+1}-\dot{R}_{r}=0 \quad \dot{R}_{r} \geq 0 \quad \forall r=1, \ldots, N_{r}
$$

4. Overall heat balance:

$$
\dot{R}_{1}=0, \dot{R}_{N_{r+1}}=0
$$

5. Electricity consumption:

$$
\sum_{s=1}^{N_{s}} f_{s} \dot{E}_{s}^{-}-\dot{E}_{c}^{+}+\varepsilon_{d} \dot{E}^{+} \geq 0
$$

6. Electricity exportation:

$$
\sum_{s=1}^{N_{s}} f_{s} \dot{E}_{s}^{-}-\dot{E}_{c}^{+}+\varepsilon_{d} \dot{E}^{+}-\frac{\dot{E}^{-}}{\varepsilon_{g}}=0
$$$$
\dot{E}^{+} \geq 0, \dot{E}^{-} \geq 0
$$

with:

$A, b \quad$ coefficients of the linear equation system defined by the superstructure

$C_{j} \quad$ weighting factor of product $j$

$f_{s} \quad$ level of utilisation of subsystem $s$

$f_{\max , s} \quad$ upper bound of $f_{s}$

$f_{\min , s} \quad$ lower bound of $f_{s}$

$N_{r} \quad$ number of temperature intervals $r$

$N_{s} \quad$ number of subsystems $s$

$\dot{Q}_{s, r}^{-} \quad$ the net production of heat of subsystem $s$ in the temperature interval $r$ for the reference

$$
\text { flowrate }
$$

$\dot{R}_{r} \quad$ cascaded energy from the temperature interval $r+1$ to $r$

$\dot{E}^{+} \quad$ the consumption of electricity from the grid

$\dot{E}_{c}^{+} \quad$ the auxiliary consumption of electricity on-site

$\dot{E}^{-} \quad$ the production of electricity to the grid

$\dot{E}_{s}^{-} \quad$ the net production of electricity of subsystem $s$ for the reference flowrate

$y_{s} \quad$ integer variable for the presence of subsystem $s$

$\varepsilon_{d} \quad$ the conversion efficiency from the grid

$\varepsilon_{g} \quad$ the conversion efficiency to the grid

Allowing for arbitrary reference flowrates of the different subsystems in the unit models (Eq. 2), the superstructure model of Eq. (7) consists of the mass balances between all subsections illustrated in Figure 2. For instance, the connection between drying, gasification and combustion is written as:

$$
\dot{m}^{+}{ }_{\text {wood }, g} f_{g}+y_{\text {wood }, c} \dot{m}^{+}{ }_{\text {wood }, c} f_{\text {wood }, c}-\dot{m}^{-}{ }_{\text {wood }, d} f_{d}=0
$$

in which $\dot{m}^{+}{ }_{\text {wood,g }, g}, \dot{m}^{+}{ }_{\text {wood }, c}$ and $\dot{m}^{-}{ }_{\text {wood }, d}$ are obtained from the unit models $\mathscr{F}_{s}$ (Eq. 2) and $y_{\text {wood,c }}$ represents the choice of the technology subset that can be used as a decision variable on the master optimisation level. The non-linearities of the thermochemical conversion are thus enclosed in the coefficient matrix $A$ of Eq. (7) and only the utilisation levels $f_{s}$ of the subsystems are computed in the MILP problem. The only non-zero entry of $b$ thereby fixes the reference scale of, for instance, the biomass input:

$$
\dot{m}^{+}{ }_{\text {wood }, d} \Delta h_{\text {wood }}^{0} f_{d}=c s t
$$

in which $\Delta h_{\text {wood }}^{0}$ refers to the lower heating value of the feedstock. 


\subsection{Combined mass and energy integration}

In general, the constraint on $\dot{R}_{N_{r+1}}$ in Eq. (9) is not feasible without hot utility or, in our case, burning the depleted and part of some intermediate product streams. The unit model for combustion is thus of particular significance since it connects the energy and mass balances in order to satisfy the heat requirement in the highest temperature interval of Eq. (8) while respecting the superstructure model of Eq. (7). Following the formulation of Maréchal and Kalitventzeff (1998), it is possible to directly determine its optimal integration in the MILP problem by dissociating the effects of fuel and air in the combustion. Defining the heat of combustion $h_{f, r}$ as the amount of heat available from the combustion gases at an arbitrary radiation temperature $T_{r}$ if the combustion is carried out with air available at this temperature, the contribution of each fuel $f$ in the heat balance above $T_{r}$ (Eq. 8) is written as:

$$
\dot{Q}_{f, r}^{-}=\dot{m}_{f} h_{f, r}-\dot{m}_{\text {air }, \text { stoich. }} c_{p, a i r}\left(T_{r}-T_{\text {air }, i n}\right)
$$

The first term of this equation thus exclusively quantifies the contribution of the fuel at $T_{r}$, and the second one the energy required to heat up the stoichiometric amount of air from the reactor inlet temperature $T_{a i r, i n}$ to $T_{r}$. For all candidate fuels identified in the process superstructure, $h_{f, r}$ can be determined from their lower heating value $\Delta h_{f}^{0}$, the adiabatic flame temperature $T^{0}{ }_{a d, f}$, the oxygen required for the complete combustion of the fuel $c_{O 2, \text { req. }}$ (in $\mathrm{kg} \mathrm{O}_{2} / \mathrm{kg}$ fuel) and the mass fraction of oxygen in air $c_{O 2, \text { air }}$ :

$$
h_{f, r}=\frac{T_{a d, f}^{0}-T_{r}}{T_{a d, f}^{0}-T^{0}} \Delta h_{f}^{0}+\frac{c_{O 2, r e q .}}{c_{O 2, a i r}} c_{p, a i r}\left(T_{r}-T^{0}\right)
$$

Similar to the effect of the fuel above $T_{r}$, its contribution in the heat balance between $T_{r}$ and the stack temperature $T_{\text {stack }}$ to be recovered by convective transfer is written as:

$$
\dot{Q}_{f, c}^{-}=\dot{m}_{f} h_{f, c}+\dot{m}_{\text {air stoich. }} c_{p, \text { air }}\left(T_{r}-T_{\text {stack }}\right)
$$

for which $h_{f, c}$ can be calculated from:

$$
h_{f, c}=\frac{T_{r}-T_{\text {stack }}}{T^{0}{ }_{a d, f}-T^{0}} \Delta h_{f}^{0}-\frac{c_{O 2, r e q .}}{c_{O 2, a i r}} c_{p, a i r}\left(T_{r}-T_{\text {stack }}\right)
$$

The heat requirement for air preheating is separately added to the problem as cold stream with:

$$
\dot{Q}_{a i r, c}^{+}=\dot{m}_{\text {air }, \text { stoich. }} c_{p, a i r}\left(T_{a i r, i n}-T^{0}\right)
$$

and its utilisation level $f_{\text {air }}$ is linked to the ones of the fuels $f_{f}$ by a constraint that allows for oxygen excess $e_{f}$ :

$$
\sum_{f=1}^{N_{f}}\left(1+e_{f}\right) c_{O 2, r e q} f_{f}-c_{O 2, a i r} f_{\text {air }, 0} \leq 0
$$

While Eq. (19) assures a sufficient air flow rate for complete combustion, the air temperature at the reactor inlet $T_{\text {air, in }}$ in Eqns. (14) and (18) is a priori unknown and needs to be computed. The equations thereby show that air preheating introduces a heat pumping effect since increasing $T_{\text {air } i n}$ allows for increasing the heat available at $T_{r}$ with heat below $T_{\text {air,in }}$. The determination of the optimal value of $T_{\text {air }, \text { in }}$ can be integrated in the MILP formulation by discretising the cold steam of Eq. (18) in $N_{i}$ intervals from $T_{i}$ to $T_{i+1}$ :

$$
\dot{Q}_{\text {air }, c}^{+}=\sum_{i=0}^{N_{i}} \dot{Q}_{\text {air }, i, c}^{+}=\dot{m}_{\text {air }, \text { stoich. }} c_{p, a i r} \sum_{i=0}^{N_{i}}\left(T_{\text {air }, i+1}-T_{\text {air }, i}\right)
$$

and constraining their flow multiplication factors with:

$$
f_{\text {air }, i} \geq f_{\text {air }, i+1} \quad \forall i=0, \ldots, N_{i}
$$




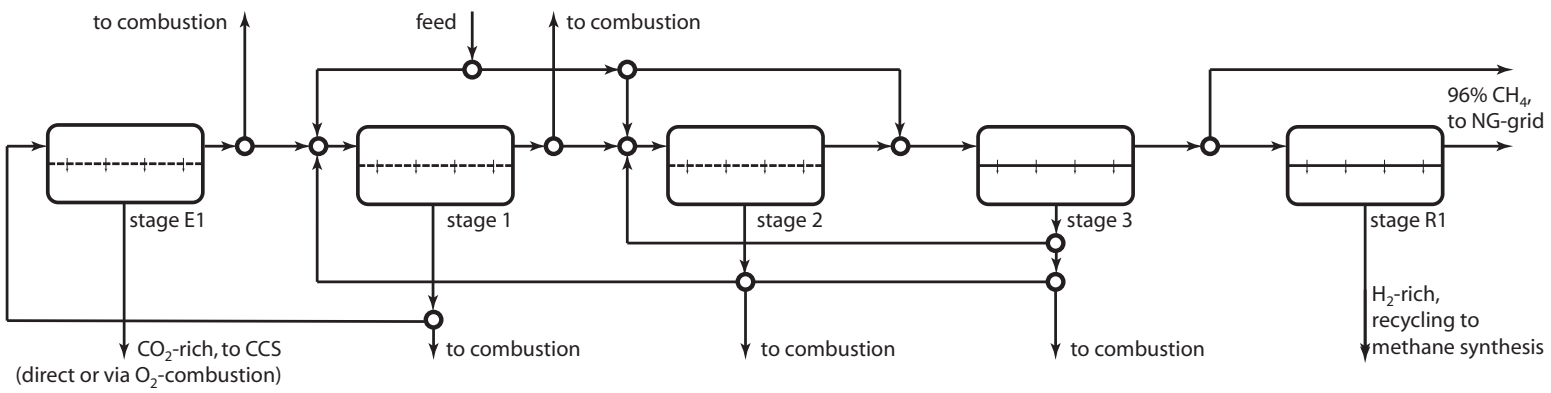

Figure 4: Superstructure of the membrane cascade.

where $f_{\text {air }, 0}$ is the multiplication factor for ambient air. Accordingly, the temperature difference in the second term of the left-hand side of Eq. (14) is written by difference as:

$$
\begin{aligned}
T_{r}-T_{a i r, i n} & =T_{r}-T^{0}-\sum_{i=0}^{N_{i}}\left(T_{i+1}-T_{i}\right) \\
& =T_{r}-\sum_{i=1}^{N_{i}}\left(T_{i+1}-T_{i}\right)
\end{aligned}
$$

In the MILP formulation, the energy recovery from the excess heat with a steam cycle is integrated according to the method of Maréchal and Kalitventzeff (1997). The superstructure of the cycle layout is thereby fixed on the master optimisation level, from which the optimal headers and their flowrates are then determined in the resolution of the MILP problem.

\section{Application to the example problem}

\subsection{Problem setup}

The system limits of the non-linear process units models in the problem decomposition are arbitrary and depend on the choice of analysis. In our case, their selection in Figure 2 has been motivated by the principal chemical conversion steps that markedly change the characteristics of the candidate fuels for balancing the process heat requirements. In the pilot installation, clean, cold producer gas is used for this purpose (Hofbauer et al., 2002). Dried wood and hot raw producer gas can be identified as promising alternatives that allow for increasing the process efficiency (Gassner and Maréchal, 2009c). Raw SNG downstream of the exothermal methane synthesis is not considered as appropriate since part of its chemical energy content is already converted to heat below the process pinch.

For the separation in a membrane cascade, a superstructure of promising candidate setups has been developed in Gassner et al. (2009). Shown in Figure 4, it consists of three main stages for the bulk separation of $\mathrm{CO}_{2}$ and $\mathrm{CH}_{4}$. Optionally, the methane is further purified from residual hydrogen in a recovery stage R1 whose permeate is recycled back to the synthesis for increasing the methane yield. In addition, it is possible to recover the by-produced carbon dioxide for capture and storage in an enriching stage E1. For stages 1 to 3 and E1, cellulose acetate has been considered as material with a good $\mathrm{CO}_{2} / \mathrm{CH}_{4}$-selectivity and proven robustness in industrial applications. For stage $\mathrm{R} 1$, a polysulfone membrane has been selected due to its better selectivity between $\mathrm{H}_{2}$ and $\mathrm{CH}_{4}$. The properties and prices used in the model are based on the data of Bhide and Stern (1993); Abetz et al. (2006); Phair and Badwal (2006) and are summarised in Gassner and Maréchal (2009b). If reliable data dependent on detailed operating conditions or other materials would be available, our approach would thereby easily allow for integrating the material choice in the global optimisation step.

Due to the many recycling streams in the membrane cascade and back to the methane synthesis, these sections of the flowsheet are nested in a highly non-linear way. Although a decomposition of this part 
of the flowsheet in a non-linear and linear problem would be possible in principle by a generalisation of the approach of Girardin et al. (2006) and Vince et al. (2008), no real benefit is expected in our case since it would require to introduce artificial multicomponent source terms for recycle loops that are relatively short. The flowsheeting of these sections is thus considered as a single non-linear unit model and entirely addressed in the global optimisation problem. The depleted streams of the membrane cascade are thereby considered as waste streams whose combustion is imposed by constraints to the MILP model. If their flame temperature is not sufficient to provide useful energy above the pinch at gasification temperature $\left(850^{\circ} \mathrm{C}\right)$, this is done in a separate catalytic combustion that fully converts all residual oxidisable substances and inhibits the emission of the highly active greenhouse gas $\mathrm{CH}_{4}$.

\subsection{Process optimisation}

Multi-objective optimisation techniques have been introduced in the conceptual design of energy conversion systems in order to provide an enlarged set of candidate solutions to a design problem that is characterised by several conflictive objectives such as efficiency, cost and environmental impact (see, for example Toffolo and Lazzaretto (2002); Lazzaretto and Toffolo (2004); Li et al. (2006) and Sayyaadi (2009) for CHP plants, Maréchal et al. (2005) and Autissier et al. (2007) for fuel cells and Brown et al. (2009) for internal gasification combined cycles). Due to their ability of handling non-linear and noncontinuous objective functions, evolutionary algorithms have thereby proven as a robust method for solving such complex programming problems.

In earlier work (Gassner et al., 2009), we have used an algorithm developed by Molyneaux et al. (2010) to discuss different design strategies for the membrane cascade based on a fixed plant layout and operating conditions in the production of the crude. According to the strategy for selecting a minimum number of appropriate objectives developed in Gassner and Maréchal (2009a), each candidate membrane configuration has been optimised with respect to three objectives. Such a setup has resulted in a population of 300-400 optimal plant configurations after 4'000 iterations. The analysis has demonstrated that the design indeed benefits from taking the process integration aspects into account. Table 2 and Figure 5 summarise the optimal membrane system configurations if the performance of only the separation system or the overall plant is considered. In an isolated cascade design, two recycle loops put much more emphasis on a high product recovery in a 3-stage system. If the design can be carried out with respect to overall performance, only one recycle loop, $37 \%$ less membrane area and $21 \%$ less compression power are required. By targeting not only the upgrade of SNG, but also the capture of the by-produced biogenic $\mathrm{CO}_{2}$, it is possible to turn the process into a sink of atmospheric $\mathrm{CO}_{2}$ if the resource is exploited in a sustainable way. The integration of an electrolysis unit that supplies both oxygen for catalytic combustion of the permeate of stage E1 and hydrogen to slightly increase the methane yield has proven suitable for this purpose.

In this work, we do not only address the design of the separation subsystem, but the simultaneous optimisation of the entire plant including the crude SNG production, its separation and the energy recovery system. In order to illustrate the influence of combined mass and energy integration, the optimisation is carried out for three exemplary problem setups for which different solutions with respect to process integration are expected:

1. The heat requirement of indirectly heated gasification is balanced with clean, cold producer gas as done in the pilot plant (Hofbauer et al., 2002). Mathematically, this translates by $y_{\text {wood,c }}=$ $y_{\text {hot gas }, c}=0$ and only $y_{\text {cold gas }, c} \in\left[\begin{array}{ll}0 & 1\end{array}\right]$ in Eq. (6) and Figure 2.

2. The fuel choice is left to the MILP problem and the constraints on $y_{\text {wood }, c}$ and $y_{\text {hot } g a s, c}$ are released to $y_{\text {wood }, c}, y_{\text {hot gas }, c} \in\left[\begin{array}{ll}0 & 1\end{array}\right]$.

3. Directly heated, pressurised steam-oxygen blown technology is used. No supplementary heat from combustion is required for the process.

The membrane subconfigurations are freely chosen in the global optimisation from the superstructure shown in Figure 4. While integer variables are used to select the number of main stages and whether 


\begin{tabular}{|c|c|c|c|}
\hline \multicolumn{2}{|c|}{$\begin{array}{l}\text { Optimal solution with respect to: } \\
\text { Operating conditions and performance }\end{array}$} & \multirow{2}{*}{$\begin{array}{r}\begin{array}{r}\text { separation } \\
\text { system }\end{array} \\
3\end{array}$} & $\begin{array}{r}\text { overall } \\
\text { plant }\end{array}$ \\
\hline$\overline{N_{\text {stages }}}$ & - & & 3 \\
\hline Feed stage & - & 2 & 1 \\
\hline Internal recycling loops & - & 2 & 1 \\
\hline Recycling to methanation & - & & not considered \\
\hline$p_{f 1}$ & bar & 12.1 & 24.4 \\
\hline$p_{f 2}$ & bar & 35.9 & 49.0 \\
\hline$p_{f 3}$ & bar & 50.0 & 49.0 \\
\hline$\theta_{1}$ & - & 0.56 & 0.39 \\
\hline$\theta_{2}$ & - & 0.52 & 0.40 \\
\hline$\theta_{3}$ & - & 0.46 & 0.24 \\
\hline$\tilde{c}_{C O 2, p 1}$ & $\%$ & 86.6 & 79.9 \\
\hline SNG recovery (separation) & $\%$ & 93.2 & 84.1 \\
\hline Power consumption (separation) & MW & 1.06 & 0.84 \\
\hline$A$ & $\mathrm{~m}^{2}$ & 4675 & 2928 \\
\hline Total energy efficiency ${ }^{a}$ & $\%$ & 66.0 & 66.2 \\
\hline Chemical efficiency ${ }^{\mathrm{b}}$ & $\%$ & 67.3 & 68.1 \\
\hline Investment, separation & $\mathrm{M} €$ & 5.7 & 4.1 \\
\hline Investment, total & $\mathrm{M} €$ & 30.7 & 29.9 \\
\hline Total production $\operatorname{cost}^{\mathrm{c}}$ & $€ / \mathrm{MWh}_{S N G}$ & 105.6 & 102.9 \\
\hline Biomass breakeven cost ${ }^{\mathrm{d}}$ & $€ / \mathrm{MWh}_{\text {wood }}$ & 42.6 & 44.2 \\
\hline
\end{tabular}

${ }^{\text {a }}$ defined as the ratio between overall production and consumption terms

$\mathrm{b}$ the electricity co-production is expressed as an SNG-equivalent and substituted therein - an exergy efficiency of 55\% is assumed for the conversion of SNG to electricity

$\mathrm{c}$ includes profit from selling by-produced electricity and equipment depreciation

$\mathrm{d}$ maximum raw material cost for which the project is overall profitable

Table 2: Comparison between isolated and integrated design approaches for fixed operating conditions of the reactive sections and without hydrogen recycling to methanation (Gassner et al., 2009). The corresponding membrane cascades are displayed in Figure 5.

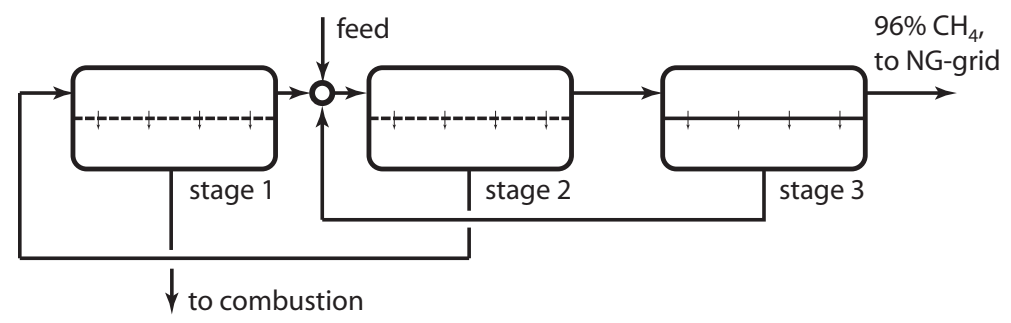

(a) Optimal configuration with respect to separation system performance (three-stage, countercurrent recycling).

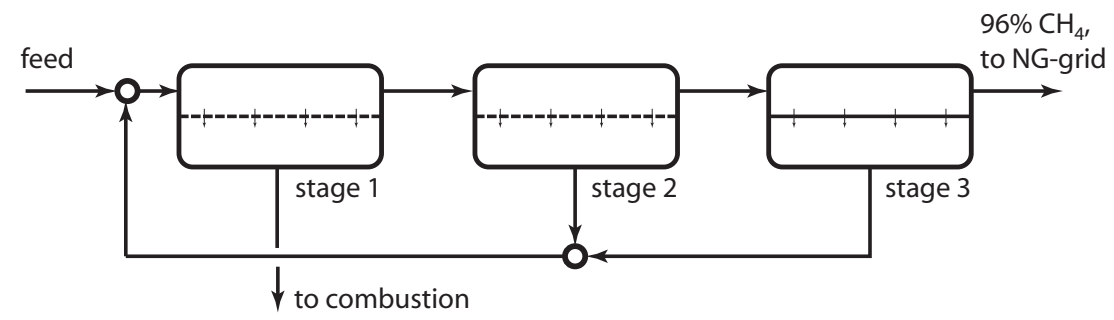

(b) Optimal configuration with respect to overall plant performance (three-stage, one common recycle loop).

Figure 5: Optimal membrane cascades for fixed operating conditions of the reactive sections and without hydrogen recycling to methanation as detailed in Table 2 (Gassner et al., 2009). 


\begin{tabular}{|c|c|c|c|c|c|}
\hline Section & Technology & Operating conditions & & Unit & Value/Range \\
\hline \multirow[t]{2}{*}{ Drying } & \multirow[t]{2}{*}{ Air drying } & Air inlet temperature & $T_{d, i n}$ & ${ }^{5} \mathrm{C}$ & {$\left[\begin{array}{lll}180 & 240\end{array}\right]$} \\
\hline & & Humidity after drying & $\Phi_{d \text { wood }}$ & $\%$ wt & {$\left[\begin{array}{lll}10 & 30\end{array}\right]$} \\
\hline \multirow[t]{6}{*}{ Gasification } & \multirow[t]{2}{*}{ Ind. heated FICFB } & Temperature & $T_{g}$ & ${ }^{\circ} \mathrm{C}$ & 850 \\
\hline & & Pressure & $p_{g}$ & bar & 1 \\
\hline & \multirow[t]{2}{*}{ Dir. heated CFB } & Temperature & $T_{g}$ & ${ }^{\circ} \mathrm{C}$ & 800 \\
\hline & & Pressure & $p_{g}$ & bar & $p_{m}$ \\
\hline & \multirow[t]{2}{*}{ - both } & Steam to dry biomass ratio & $r_{S / B}$ & - & 0.5 \\
\hline & & Steam $/ \mathrm{O}_{2}$ preheat temperature & $T_{g, p h}$ & ${ }^{\circ} \mathrm{C}$ & 300 \\
\hline \multirow[t]{3}{*}{ Methane synthesis } & \multirow[t]{3}{*}{ Internally cooled FB } & Inlet temperature & $T_{m, i n}$ & ${ }^{\circ} \mathrm{C}$ & [300 400] \\
\hline & & Outlet temperature & $T_{m, \text { out }}$ & ${ }^{\circ} \mathrm{C}$ & [300 400] \\
\hline & & Pressure & $p_{m}$ & bar & {$\left[\begin{array}{ll}1 & 30\end{array}\right]$} \\
\hline \multirow[t]{11}{*}{ Gas separation } & \multirow[t]{11}{*}{ Membranes } & Number of main stages & $N_{\text {stages }}$ & - & [2 3] \\
\hline & & Use of recycling stage R1 & $y_{m, \text { rec. }}$ & - & {$\left[\begin{array}{ll}0 & 1\end{array}\right]$} \\
\hline & & Feed pressure of stage 1 & $p_{f 1}$ & bar & [5 50] \\
\hline & & Feed pressure of stage 2 & $p_{f 2}$ & bar & [5 50] \\
\hline & & Feed pressure of stage 3 & $p_{f 3}$ & bar & [5 50] \\
\hline & & Permeate pressure (all stages) & $p_{p}$ & bar & 1 \\
\hline & & Stage cut of stage 1 & $\theta_{1}$ & - & {$\left[\begin{array}{ll}0.2 & 0.6\end{array}\right]$} \\
\hline & & Stage cut of stage 2 & $\theta_{2}$ & - & {$\left[\begin{array}{ll}0.2 & 0.6\end{array}\right]$} \\
\hline & & Methane purity before stage R1 & $\tilde{c}_{C H_{4}, f R 1}$ & $\%$ vol & [80 96] \\
\hline & & Grid pressure & $p_{\text {grid }}$ & bar & 50 \\
\hline & & Methane purity at grid & $\tilde{c}_{C_{4}, \text { grid }}$ & $\%$ vol & 96 \\
\hline \multirow[t]{5}{*}{ Steam network } & \multirow[t]{2}{*}{ Production header } & Production pressure & $p_{s, p}$ & bar & [40 120] \\
\hline & & Superheat temperature & $T_{s, s}$ & ${ }^{\circ} \mathrm{C}$ & {$\left[\begin{array}{lll}350 & 550\end{array}\right]$} \\
\hline & \multirow[t]{3}{*}{ Utilisation headers } & Number of utilisation levels & $N_{s, u}$ & - & [14] \\
\hline & & Temperature of utilisation level $3^{\mathrm{a}}$ & $T_{s, u 3}$ & ${ }^{\circ} \mathrm{C}$ & {$\left[\begin{array}{ll}50 & 250\end{array}\right]$} \\
\hline & & Condensation level temperature ${ }^{\mathrm{b}}$ & $T_{s, c}$ & ${ }^{\circ} \mathrm{C}$ & 20 \\
\hline
\end{tabular}

a levels 1 and 2 are adjusted to steam requirements for gasification and methanation

b corresponds also to lowest utilisation level

Table 3: Principal fixed operating conditions and decision variables (except the split ratios at the stream bifurcations of Figure 4) of the global optimisation problem.

a recycling stage is added or not, the cascade layout is determined with the split ratios at the stream bifurcations as decision variables. In order not to complicate the analysis, $\mathrm{CO}_{2}$-recovery in an enriching stage (E1) and the choice of individual materials for each membrane stage is disregarded. A summary of all decision variables for the pretreatment, reactive, separation and energy recovery sections is given in Table 3. As raw material, wood with the same properties as in Gassner et al. (2009) is considered and the plant scale is fixed to $20 \mathrm{MW}_{t h, \text { wood }}$.

In the conceptual design methodology, we aim at uncoupling the generated set of optimal solutions from weighting parameters by selecting the mathematical objectives for the global optimisation problem in order to include the optima of all relevant performance indicators (Gassner and Maréchal, 2009a). In the polygeneration case presented here, three objectives, i.e. the SNG and electricity yield as well as the specific investment cost, are sufficient for entirely representing the thermo-economic performance for a fixed biomass input. Due to an increased number of decision variables in the optimisation problem, 20'000 iterations have been carried out by parallel computing on a high-performance cluster (EPFL Pleiades cluster, last visited 11/2009) and resulted in a population of 2'000-2'500 optimal plant configurations for each case shown in Figure 6. After the optimisation step, the configurations that maximise the profitability of the biomass resource for the economic conditions of Table 4 are selected from all optimal candidate solutions. The sensitivity to the weighting parameters is discussed in Section 3.3.2. 


\begin{tabular}{lr}
\hline Parameter & Value \\
\hline Marshall and Swift index (2006) & 1302 \\
Dollar exchange rate & $1 \mathrm{US} \$ / €$ \\
Interest rate & $6 \%$ \\
Discount period & 15 years \\
Plant availability & $90 \%$ \\
Operators ${ }^{\mathrm{a}}$ & $4 \mathrm{p} . / \mathrm{shift}$ \\
Operator salary & 60 '000€/year \\
Maintenance costs & $33 € / \mathrm{MWh}$ \\
Wood price $\left(\Phi_{\text {wood }}=50 \%\right)$ & $180 € / \mathrm{MWh}$ \\
Electricity price $($ green $)$ & $105 € / \mathrm{MWh}$ \\
Biodiesel price & $120 € / \mathrm{MWh}$ \\
SNG price & $5 \% /$ year of investment \\
\hline${ }^{a}$ Full time operation requires three shifts per day. With a working time of five days per week and 48 weeks per year, one \\
$\quad$ operator per shift corresponds to 4.56 employees.
\end{tabular}

Table 4: Assumptions for process economics.

\subsection{Results and discussion}

\subsubsection{Optimal process design for SNG production}

For all three process setups and the economic conditions of Table 4, the membrane layout for an overall most profitable plant design consists in two main stages with internal recycling and a subsequent hydrogen recovery and recycling stage. As shown in Figure 7, the raw SNG is thereby entirely fed to stage 1 whose permeate is burnt. Compared to other configurations that allow for higher gas yields as for instance the one in Figure 5(a) (Gassner et al., 2009), this cascade provides the best compromise between SNG recovery, power consumption, energy recovery from the depleted streams and investment cost. Although the economically optimal cascade structure is the same, its operation yet adapts to the process technology and its specific operating conditions. This is illustrated by the optimal values of the decision variables and principal characteristics of the membrane system shown in Table 5.

The constraint of operating indirectly heated gasification at atmospheric pressure (cases 1 and 2) affects the entire process design. The compression of voluminous raw producer gas is costly and methanation is preferably carried out at only moderately pressurised conditions. After the synthesis, the raw SNG is then further compressed to allow for an efficient separation. If gasification is carried out under pressure (case 3), the staged compression can be omitted and gasification, methane synthesis and the first membrane stage are best close-coupled at roughly 25 bar.

Comparing the restricted with free fuel choice in cases 1 and 2, respectively, the advantage of a combined optimisation of the energy and mass balances becomes evident. According to Table 6, dry wood is the fuel of choice to balance the heat requirement of indirectly heated gasification. Since it is withdrawn at an early stage of the conversion chain, a decreased utilisation level inherently limits the heat demand for gasification and less heat is further lost in the exothermal methane synthesis. Compared to the use of cold, clean producer gas (case 1) in which one third of the heat demand is covered with membrane permeate, a higher contribution of intermediate product in the overall heat balance is thus observed.

As indicated by a lower feed methane concentration and an increased cut in stage R1, cases 2 and 3 put more emphasis on gas recycling. In case 1, heat recovery at high temperature from the depleted stream with lower inert concentration is more important. Through an increased flame temperature, the heat contribution $h_{f, r}$ at radiation temperature is thus higher (cf. Eq. 15) and allows for limiting the flowrate required to satisfy the heat demand of gasification. Due to the absence of a pinch point at high temperature, the flame temperature is lowest in case of directly heated gasification. Possibly under catalytic action, the combustion of the permeate contributes to a high conversion efficiency by power 


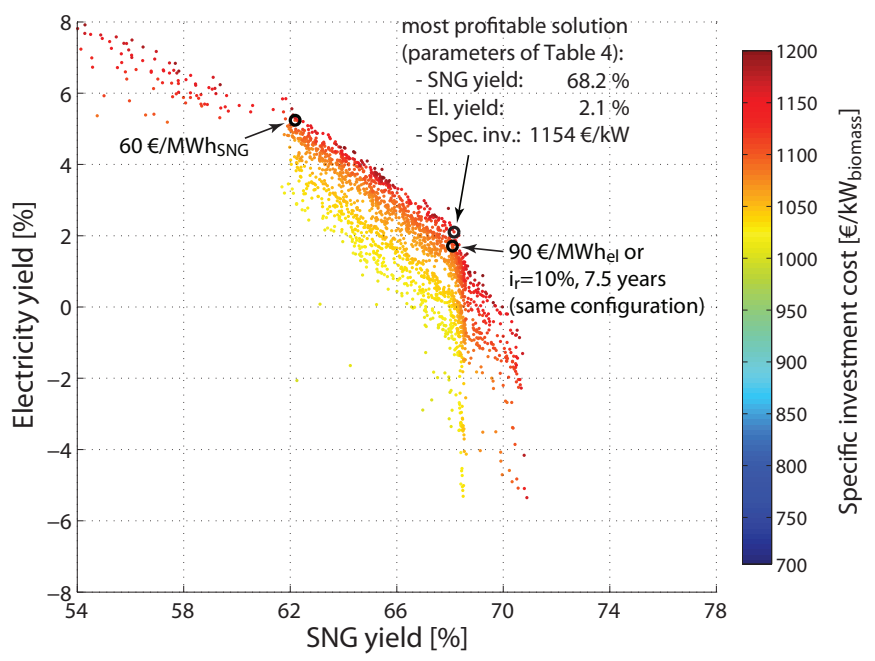

(a) Indirectly heated gasification balanced with clean, cold producer gas (case 1).

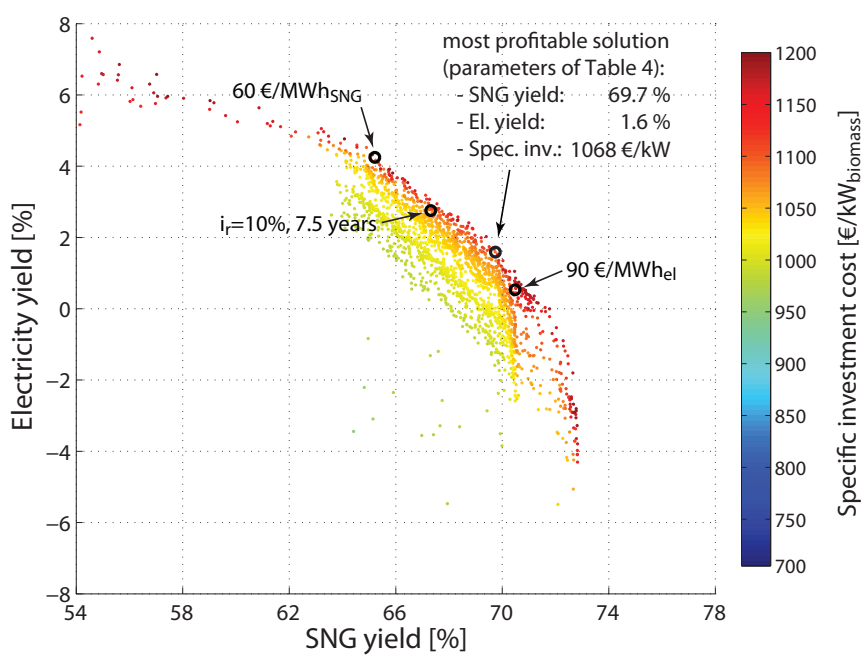

(b) Indirectly heated gasification with fuel choice by MILP (case 2).

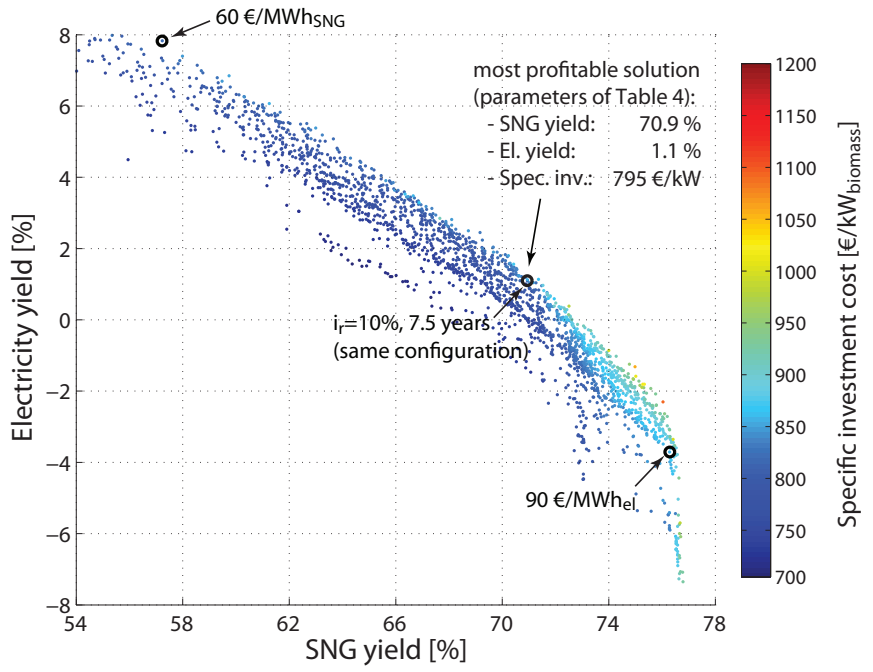

(c) Directly heated, pressurised steam-oxygen gasification (case 3).

Figure 6: Most profitable solutions in the objective space. 


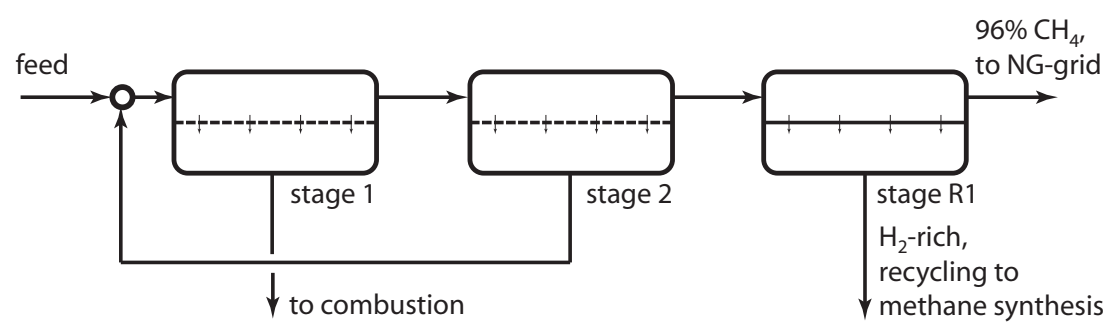

Figure 7: Most profitable membrane configuration obtained from an overall plant optimisation as detailed in Table 5.

\begin{tabular}{llrrr}
\hline & Case & 1 & 2 & 3 \\
\hline$T_{d, \text { in }}$ & ${ }^{\circ} \mathrm{C}$ & 232 & 238 & 239 \\
$\Phi_{d, \text { wood }}$ & $\% \mathrm{wt}$ & 10.0 & 10.4 & 10.5 \\
$p_{g}$ & $\mathrm{bar}$ & 1.1 & 1.1 & 25.7 \\
$T_{m, \text { in }}$ & ${ }^{\circ} \mathrm{C}$ & 382 & 400 & 367 \\
$T_{m, \text { out }}$ & ${ }^{\circ} \mathrm{C}$ & 363 & 337 & 340 \\
$p_{m}$ & $\mathrm{bar}$ & 5.7 & 6.3 & 25.5 \\
\hline$N_{\text {stages }}$ & - & 2 & 2 & 2 \\
$y_{m, r e c .}$ & - & 1 & 1 & 1 \\
$p_{f 1}$ & $\mathrm{bar}$ & 26.3 & 33.6 & 25.7 \\
$p_{f 2}$ & $\mathrm{bar}$ & 31.8 & 39.0 & 47.7 \\
$\theta_{1}$ & - & 0.43 & 0.40 & 0.47 \\
$\theta_{2}$ & - & 0.26 & 0.27 & 0.28 \\
$\theta_{R 1}$ & - & 0.14 & 0.18 & 0.18 \\
$\tilde{c}_{C H_{4}, f R 1}$ & 88.8 & 86.7 & 85.3 \\
$\tilde{c}_{C O 2, p 1}$ & $\%$ & 86.2 & 89.9 & 93.4 \\
$T^{0}{ }_{a d, p 1}$ & $\%$ & 1328 & 1191 & 1039 \\
$A$ & 1733 & 1359 & 1482 \\
\hline$p_{s, p}$ & ${ }^{\circ} \mathrm{C}$ & 116.6 & 101.4 & 120.0 \\
$T_{s, s}$ & $\mathrm{~m}^{2}$ & 547 & 547 & 550 \\
$N_{s, u}$ & $\mathrm{bar}$ & 3 & 4 & 3 \\
$T_{s, u 3}$ & ${ }^{\circ} \mathrm{C}$ & 221 & 138 & 153 \\
\hline
\end{tabular}

Table 5: Decision variables and main characteristics of the separation system design for the most profitable process configurations. The corresponding membrane cascade is displayed in Figure 7.

generation in a rather ambitious steam cycle design. Being the most efficient, this process configuration is also clearly the most economic since an adapted, compact design of all sections allows for low investment expenses.

\subsubsection{Importance of the process design approach}

As demonstrated in Gassner et al. (2009) and summarised in Table 2, a systematic process synthesis approach that integrates the reaction and separation subsystems results in more efficient and economic plants than the ones designed in conventional, isolated workpackages. These process intensification effects are amplified if an overall process optimisation is conducted. Part of the increased performances observed in Table 6 are doubtlessly due to the optimisation of the reaction system itself - they are yet difficult to detect and realise without a correct appreciation of the system interactions. The mathematical decomposition of the design problem presented here allows for an efficient simultaneous optimisation of the production and utility systems including the optimal fuel choice and combined heat and power production.

A further advantage of the proposed optimisation strategy is that the generated set of candidate process configurations is largely independent on weighting parameters. On Figure 6, this is demonstrated by 


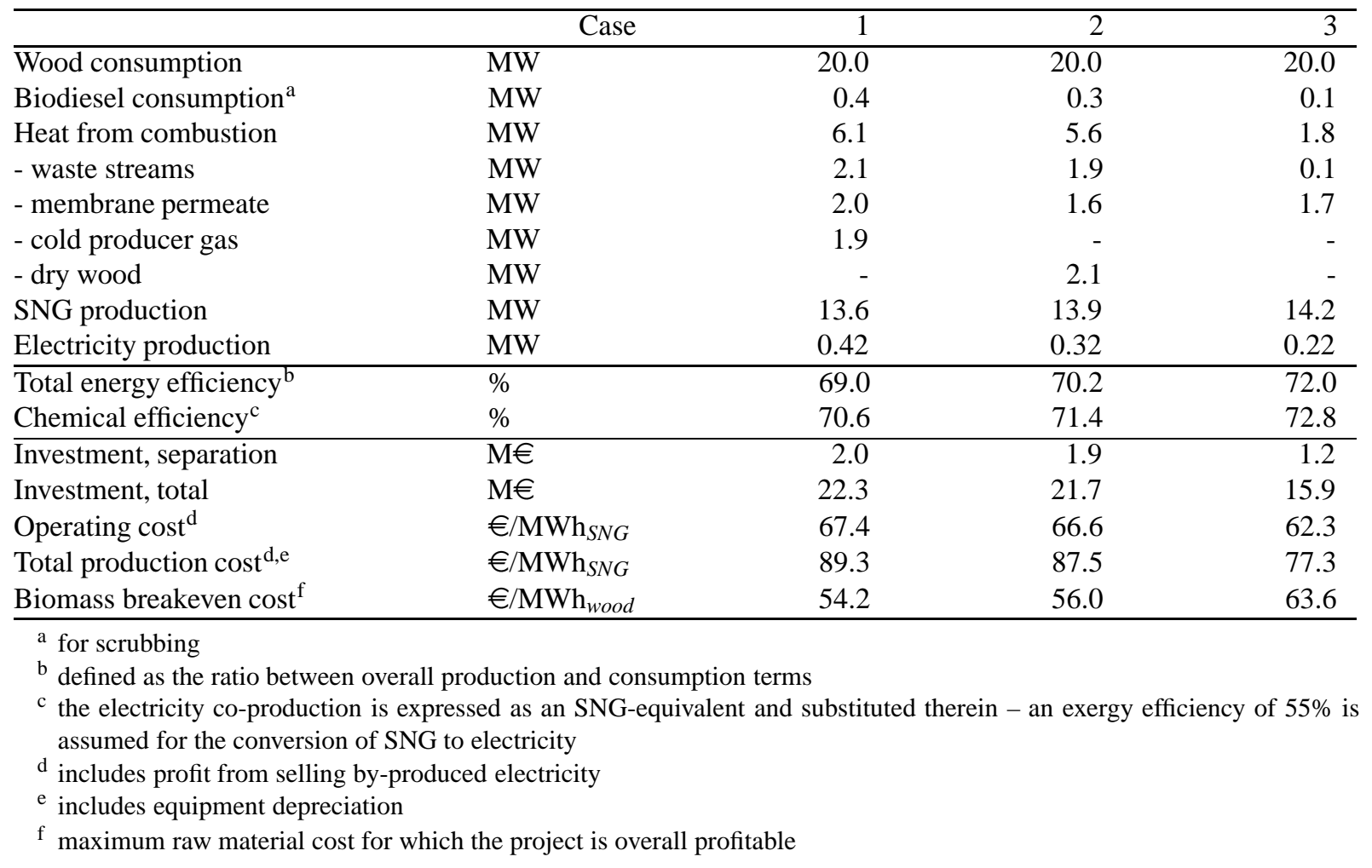

Table 6: Energy balance, efficiencies and costs of the most profitable process configurations.

identifying the most profitable configurations for different electricity prices, SNG prices or investmentrelated parameters like the interest rate and depreciation period. Such alterations impact the optimal process design considerably. This highlights that weighting the affected thermo-economic terms after the optimisation step saves not only computation time but, more importantly, also enhances the understanding of the process characteristics and sensitivities.

\section{Conclusions}

An approach for combined mass and energy integration based on an appropriate decomposition of a process design model into its non-linear and linear parts has been presented and illustrated at SNG production from biomass. By subdividing the process superstructure in non-linear units and using their relative mass flows as constraints, it is possible to simultaneously resolve the mass balances and energy integration by MILP that targets the maximum combined production of fuel, heat and power.

In this way, the synthesis of a chemical process and its separation system can be considered together with the valorisation of the waste streams as heat source for the process integration and energy recovery. In a process that only uses waste and intermediate product streams instead of external utilities, such an approach makes it possible to identify the overall optimal flowsheet structure and fuels to balance its heat demand. The application to an example case in fuel production from biomass has shown that this allows for designing more economic and efficient plants due to process intensification.

\section{Acknowledgements}

The authors acknowledge funding provided by the Competence Centre for Energy and Mobility (CCEM$\mathrm{CH}$ ), Erdgas Ostschweiz AG, Gasverbund Mittelland AG and Gaznat SA (all Switzerland). 


\section{References}

Abetz, V., Brinkmann, T., Dijkstra, M., Ebert, K., Fritsch, D., Ohlrogge, K., Paul, D., Peinemann, K.-V., Nunes, S. P., Scharnagl, N., Schossig, M., 2006. Developments in membrane research: From material via process design to industrial application. Advanced Engineering Materials 8, 328-358.

Agrawal, R., 1997. A simplified method for the synthesis of gas separation membrane cascades with limited numbers of compressors. Chemical Engineering Science 52 (6), 1029-1044.

Autissier, N., Palazzi, F., Marechal, F., van Herle, J., Favrat, D., 2007. Thermo-economic optimization of a solid oxide fuel cell, gas turbine hybrid system. Journal of Fuel Cell Science and Technology 4 (2), 123-129.

Bagajewicz, M. J., Pham, R., Manousiouthakis, V., 1998. On the state space approach to mass/heat exchanger network design. Chemical Engineering Science 53 (14), 2595-2621.

Belsim SA, last visited 04/2009. Vali IV. www.belsim.com.

Bhide, B., Stern, S., 1993. Membrane processes for the removal of acid gases from natural gas. I. Process configurations and optimization of operating conditions. Journal of Membrane Science 81, 209-237.

Biollaz, S., Schildhauer, T., Ulrich, D., Tremmel, H., Rauch, R., Koch, M., 2009. Status report of the demonstration of BioSNG production on a $1 \mathrm{MW}$ scale in Güssing. In: 17th European Biomass Conference and Exhibition. Hamburg, Germany.

Brown, D., Gassner, M., Fuchino, T., Maréchal, F., 2009. Thermo-economic analysis for the optimal conceptual design of biomass gasification energy conversion systems. Applied Thermal Engineering $29,2137-2152$.

Douglas, J. M., 1988. Conceptual design of chemical processes. McGraw-Hill, New York.

Dunn, R. F., El-Halwagi, M. M., 2003. Process integration technology review: Background and applications in the chemical process industry. Journal of Chemical Technology and Biotechnology 78 (9), $1011-1021$.

El-Halwagi, M. M., 1992. Synthesis of reverse-osmosis networks for waste reduction. AIChE Journal $38(8), 1185-1198$.

El-Halwagi, M. M., Manousiouthakis, V., 1989. Synthesis of mass exchange networks. AIChE Journal $35(8), 1233-1244$.

EPFL Pleiades cluster, last visited 11/2009. pleiades.epfl.ch.

Gassner, M., Baciocchi, R., Maréchal, F., Mazzotti, M., 2009. Integrated design of a gas separation system for the upgrade of crude SNG with membranes. Chemical Engineering and Processing 48, $1391-1404$

Gassner, M., Maréchal, F., 2009a. Methodology for the optimal thermo-economic, multi-objective design of thermochemical fuel production from biomass. Computers and Chemical Engineering 33, 769-781.

Gassner, M., Maréchal, F., 2009b. Thermo-economic process model for thermochemical production of Synthetic Natural Gas (SNG) from lignocellulosic biomass. Biomass and Bioenergy 33, 1587-1604.

Gassner, M., Maréchal, F., 2009c. Thermodynamic comparison of the FICFB and Viking gasification concepts. Energy 34, 1744-1753. 
Girardin, L., Maréchal, F., Tromeur, P., 2006. Methodology for the design of industrial hydrogen networks and the optimal placement of purification units using multi-objective optimisation techniques. In: 16th European Symposium on Computer Aided Process Engineering and 9th International Symposium on Process Systems Engineering.

Grossmann, I.E., D. M., 1996. New trends in optimization-based approaches to process synthesis. Computers and Chemical Engineering 20 (6-7), 665-683.

Hofbauer, H., Rauch, R., Löeffler, G., Kaiser, S., Fercher, E., Tremmel, H., 2002. Six years experience with the FICFB-gasification process. In: Proceedings of the 12th European Conference and Technology Exhibition on Biomass for Energy, Industry and Climate Protection. Amsterdam, Netherlands.

Isafiade, A., Fraser, D., 2009. Interval based MINLP superstructure synthesis of combined heat and mass exchanger networks. Chemical Engineering Research and Design 87 (11), 1536-1542.

Kravanja, Z., Glavic, P., 1997. Cost targeting for HEN through simultaneous optimization approach: a unified pinch technology and mathematical programming design of large HEN. Computers and Chemical Engineering 21, 833-853.

Lazzaretto, A., Toffolo, A., 2004. Energy, economy and environment as objectives in multi-criterion optimization of thermal systems design. Energy 29 (8), 1139-1157.

Li, H., Marchal, F., Burer, M., Favrat, D., 2006. Multi-objective optimization of an advanced combined cycle power plant including CO2 separation options. Energy 31 (15), 3117-3134.

Maréchal, F., Kalitventzeff, B., 1997. Identification of the optimal pressure levels in steam networks using integrated combined heat and power method. Chemical Engineering Science 52 (17), 29772989.

Maréchal, F., Kalitventzeff, B., 1998. Process integration: Selection of the optimal utility system. Computers and Chemical Engineering 22, S149-S156.

Maréchal, F., Palazzi, F., Godat, J., Favrat, D., 2005. Thermo-economic modelling and optimisation of fuel cell systems. Fuel Cells 5, 5-24.

Molyneaux, A., Leyland, G., Favrat, D., 2010. Environomic multi-objective optimisation of a district heating network considering centralized and decentralized heat pumps. Energy 35 (2), 751-758.

Mozaffarian, M., Zwart, R. W. R., 2003. Feasibility of biomass/waste-related SNG production technologies. Tech. rep., ECN, Petten.

Pettersen, T., Lien, K., 1994. A new robust design model for gas separating membrane modules, based on analogy with counter-current heat exchangers. Computers and Chemical Engineering 18 (5), 427-439.

Phair, J., Badwal, S., 2006. Materials for separation membranes in hydrogen and oxygen production and future power generation. Science and Technology of Advanced Materials 7, 792-805.

Qi, R., Henson, M. A., 2000. Membrane system design for multicomponent gas mixtures via mixedinteger nonlinear programming. Computers \& Chemical Engineering 24 (12), 2719 - 2737.

Sayyaadi, H., 2009. Multi-objective approach in thermoenvironomic optimization of a benchmark cogeneration system. Applied Energy 86 (6), 867-879.

Tijmensen, J. A. M., Faaij, A. P. C., Hamelinck, C. N., van Hardeveld, M. R. M., 2002. Exploration of the possibilities for production of Fischer Tropsch liquids and power via biomass gasification. Biomass and Bioenergy 23, 129-152. 
Tock, L., Gassner, M., Maréchal, F., 2010. Thermo-economic process model for thermochemical production of liquid fuels from lignocellulosic biomass. Accepted for publication in Biomass and Bionenergy.

Toffolo, A., Lazzaretto, A., 2002. Evolutionary algorithms for multi-objective energetic and economic optimization in thermal system design. Energy 27 (6), 549-567.

Vince, F., Marechal, F., Aoustin, E., Bréant, P., 2008. Multi-objective optimization of ro desalination plants. Desalination 222, 96-118. 